\title{
VDRL SLIDE FLOCCULATION REACTION FOR SYPHILIS PERFORMED ON ACTIVE SERA*†
}

\author{
BY \\ EKKEHARD E. SCHMID AND T. VELAUDAPILLAI \\ Medical Research Institute, Colombo, Ceylon
}

The discovery of cardiolipin (Pangborn, 1941a) as the active agent in antigens for sero-reactions for syphilis enabled the production of chemically defined antigens, composed of cardiolipin, purified lecithin (Pangborn, 1941b), and cholesterol.

Among the many tube and slide flocculation reactions based on the use of cardiolipin antigens, the Venereal Disease Research Laboratory (VDRL) slide flocculation reaction for syphilis, as described in the Manual of Serologic Tests for Syphilis (1949), has gained a world-wide reputation because of its specificity, sensitivity, and simplicity.

All the well established sero-reactions for syphilis except two-the Meinicke tube and slide flocculation reactions (Meinicke, 1917 ; Meinicke and Holthaus, 1933 ; Meinicke and Fischer, 1939 ; Kvittingen, 1948 ; Schmid and Velaudapillai, 1953) and the Citochol slide flocculation (Schmid and others, 1953) - depend on the use of inactivated sera. Whether this inactivation is performed at $56^{\circ} \mathrm{C}$. for $30 \mathrm{~min}$. or at higher temperatures for a shorter time, there is always the need of special equipment, the risk of sera becoming unsuitable for the test, and the risk of loss of time.

The postulation of chemically defined and hence uniform batches of antigens is not met by the antigens for the Meinicke and Citochol reactions on active sera, because the former (though Meinicke and Brauer (1953) reported on the use of cardiolipin in its composition) contains balsam of Tolu, which is not a chemically defined substance, instead of cholesterol, and the latter antigen belongs to the group of " crude" heart extract antigens.

It seemed therefore worth while experimenting to develop a VDRL test modified for the use of active sera.

\footnotetext{
* Received for publication September 7, 1954.

+Paper read to the Tagung fuer Mikrobiologie und Hygiene,

Innsbruck, Austria, September, 1954.
}

\section{Methods}

Stabilization of active sera, similar to that of heat inactivation, can be obtained by the use of hypertonic saline (Sachs, 1921 ; Sachs and Georgi, 1921 ; Georgi and Lebenstein, 1921). The influence of various saline concentrations, of various concentrations of cardiolipin, lecithin, and cholesterol, and of the presence or absence of formalin, which is known to act as an inhibitor (Dold, 1921 ), was carefully studied on 25,645 active sera in parallel with the original VDRL test using the same but inactivated sera. In the same way the influence of different speeds of rotation (Klein and others, 1952), and of varying " ripening" times of the prepared new antigen emulsion was also investigated.

From the knowledge thus gained on the interactions of these variables, we were able to specify the technical requirements of a new test.

\section{Technique}

The general equipment for this reaction is the same as for the original VDRL test, except that capillary pipettes with rubber teats were used. These capillary pipettes are cut at the 56 hole of Starret's gauge, and deliver $0.025 \mathrm{ml}$. serum or saline per drop. The amount of antigen emulsion delivered is $0.021 \mathrm{ml}$. per drop.

Buffered saline solutions of 1,4 , and 10 per cent. sodium chloride are required. They are best made by preparing 1 and 10 per cent. solutions separately. The second (10 per cent.) is diluted $1: 2.5$ with distilled water to yield the required lower concentration of 4 per cent. sodium chloride. This dilution should be freshly prepared every working day. The formula of these buffered saline solutions is the same as for the original VDRL test, except that $100 \mathrm{~g}$. sodium chloride per litre is used to prepare the $10 \mathrm{per}$ cent. solution.

Sera.-These are separated from the clot, and, if necessary, freed from red corpuscles by centrifuging, and are then ready for use. 
Antigen.-Commercially available VDRL antigen.

Preparation of Antigen Emulsion.-Pipette $0.75 \mathrm{ml}$. 1 per cent. buffered saline to the bottom of a $40 \mathrm{ml}$. bottle.

Add $1.05 \mathrm{ml}$. antigen directly into the saline while rotating the bottle gently but continuously on a flat surface. Approximately $10 \mathrm{sec}$. is allotted for this procedure. Continue rotating for 20 more seconds. Avoid splashing saline on the antigen pipette.

Add $8.2 \mathrm{ml}$. 1 per cent. buffered saline, close the bottle, and mix well by vigorous shaking for $30 \mathrm{sec}$.

Add $5.0 \mathrm{ml} .10$ per cent. buffered saline, close the bottle, and mix well by vigorous shaking for $30 \mathrm{sec}$.

The antigen emulsion is left for $15 \mathrm{~min}$. at room temperature for ripening, and is then ready for use. This amount is sufficient for about $\mathbf{3 5 0}$ sera. It is tested on known positive, doubtful, and negative sera. If more sera are to be examined, twice that amount may be prepared in one procedure. If still larger quantities of antigen emulsion are required, it is advisable to prepare it in separate mixtures and to pool these preparations in a suitable bottle.

Experiments were carried out to evaluate the storage quality of the antigen emulsion by keeping it in the refrigerator $\left(4^{\circ} \mathrm{C}\right.$.) for 11 days with comparative daily tests on a total of 1,505 sera. It was found that the antigen emulsion remains usable for 4 days, which we consider of economic advantage to smaller laboratories where less than 350 sera were examined per day. It is important to resuspend the particles of the emulsion by gentle shaking when the bottle containing the antigen has been allowed to stand.

It cannot be over-emphasized that all measurements for the preparation of the antigen emulsion are to be made with great accuracy. To avoid measuring small fractions of a millilitre we thought it advisable to try an antigen specially prepared to suit the requirements of this new sero-reaction with simple measurements.

With this antigen (Istituto Sieroterapico Vaccinogeno Toscano "SCLAVO", Siena, Italy), the preparation of the antigen emulsion follows the procedure of the original VDRL test except for the addition of 10 per cent. saline, i.e. :

$0.4 \mathrm{ml}$. 1 per cent. buffered saline $+0.5 \mathrm{ml}$. antigen $+4.1 \mathrm{ml}$. 1 per cent. buffered saline + $2.5 \mathrm{ml}$. 10 per cent. buffered saline.

The requirements for timing, rotation, shaking, ripening, and preparation of larger batches, as described above, must also be observed. This amount of antigen emulsion is sufficient for about 170 sera.
Performance of the Test.-All measurements of the test are made with the capillary pipettes described above. Washing the pipettes three times in physiological saline and blowing them against a filterpad after each step permits the same pipette to be used throughout the test.

One drop of the serum is distributed into each wax ring, then one drop of antigen is added and the slides are rotated at 120 r.p.m. for $4 \mathrm{~min}$. with a rotating diameter of 2 in.

Another drop of antigen and one drop of 4 per cent. buffered saline are then added to each wax ring and the slides are rotated at the same speed for another $3 \mathrm{~min}$. Then the results are read by the naked eye or with the help of a hand lens $(\times 6)$.

In hot dry climates the use of a moist chamber may be necessary for the first rotation to avoid undue evaporation. If no electric rotator is available, rotation can easily be carried out by hand on a flat surface.

The results are recorded as negative $(-)$ showing a homogenous opacity, doubtful $( \pm)$ with a few and small flocculations, and positive $(+)$ with more and larger aggregates, up to clarification with very large and scattered particles.

\section{Results}

The results obtained with this new technique in 15,000 sera, are compared with the VDRL test on the same but inactivated sera (Table I).

TABLE I

\begin{tabular}{|c|c|c|c|c|c|c|}
\hline \multirow{6}{*}{ שू } & & \multicolumn{5}{|c|}{ Inactivated Sera } \\
\hline & & - & \pm & + & Total & Percentage \\
\hline & - & 13,163 & 83 & 50 & 13,296 & $88.64 \pm 0.26$ \\
\hline & \pm & 88 & 88 & 101 & 277 & $1 \cdot 85 \pm 0.11$ \\
\hline & + & 36 & 64 & 1,327 & 1,427 & $9 \cdot 51 \pm 0.24$ \\
\hline & Total & 13,287 & 235 & 1,478 & 15,000 & \\
\hline & $\begin{array}{c}\text { Per- } \\
\text { centage }\end{array}$ & $88.58 \pm 0.26$ & $1 \cdot 57 \pm 0 \cdot 10$ & $9.85 \pm 0 \cdot 24$ & & \\
\hline
\end{tabular}

None of the listed differences between these two tests is statistically significant, as they are all covered by less than a two-fold standard deviation.

When the results of comparing the two tests are reported in percentages of agreement, it is evident that a large number of non-reactive sera contributes favourably towards a high percentage of agreement. The evaluation of the percentage of agreement among reactive sera is therefore considered to be a more representative figure (Table II, opposite).

The agreement between these two reactions is very high, i.e. 98.29 and 86.01 per cent. respectively. The $\chi^{2}$ test was applied to these figures and proved that 
TABLE II

\begin{tabular}{|c|c|c|c|c|c|c|c|}
\hline \multicolumn{5}{|c|}{ Number of Sero-reactions } & \multirow{3}{*}{$\begin{array}{c}\text { Per- } \\
\text { centage } \\
\text { Agree- } \\
\text { ment }\end{array}$} & \multirow{3}{*}{$\begin{array}{c}\text { Per- } \\
\text { centage } \\
\text { Reactors }\end{array}$} & \multirow{3}{*}{\begin{tabular}{|c|} 
Percentage \\
Agreemen \\
among \\
Reactors
\end{tabular}} \\
\hline Inactive & - & - & $\mathbf{R}$ & $\mathbf{R}$ & & & \\
\hline Active & - & $\mathbf{R}$ & - & $\mathbf{R}$ & & & \\
\hline Total & 13,163 & 124 & 133 & 1,580 & $98 \cdot 29$ & $12 \cdot 25$ & 86.01 \\
\hline
\end{tabular}

the different numbers of reactive sera for each test are statistically not significant $\left(\chi^{2}=0 \cdot 3375\right)$.

\section{Discussion}

The above results show that our new test using active sera equals the VDRL test on inactivated sera.

We have omitted a separate analysis of clinically diagnosed sera for two main reasons :

(i) The sensitivity and specificity of the VDRL test is well established.

(ii) Previous experience (Schmid and others, 1953) has shown that the number of clinically diagnosed sera is only about 15 per cent. of the total sera investigated.

This new modification of the VDRL test offers three definite advantages:

(1) work with active sera;

(2) use of simple drop pipettes;

(3) ability to store the antigen emulsion for 4 days.
The postulation of a chemically defined antigen is also met.

\section{Summary}

A new modification of the VDRL slide flocculation reaction for the use of active sera is described.

We wish to thank the Istituto Sieroterapico Vaccinogeno Toscano "SCLAVO", Siena, Italy, for putting at our disposal various batches of the modified new antigen along with their "Microgen" brand of VDRL antigen.

Our thanks are also due to Messrs N. E. L. Ponnuswamy and A. L. Dassanayake, for their assistance in performing the various tests in the laboratory.

\section{REFERENCES}

Dold, H. (1921). Dtsch. med. Wschr., 47, 1485.

Georgi, F., and Lebenstein, H. (1921). Z. ImmunForsch., 33, 503.

Klein, S. J., Konwaler, B. E., and Goldkind, P. S. (1952). J. Lab. clin. Med., 40, 146.

Kvittingen, J. (1948). Acta path. microbiol. scand., 25, 767.

Meinicke, E. (1917). Berl. klin. Wschr., 54, 613.

-

__, and Brauer, A. (1953). Klin. Wschr., 31, 665.

-

Pangborn, M. C. (1941a). Proc. Soc. exp. Biol. (N. Y.), 48, 484.

(1941b). J. biol. Chem., 137, 545.

Public Health Service, Federal Security Agency (1949). “Manual of Serologic Tests for Syphilis", J. vener. Dis. Inform., Suppl. No. 22.

Sachs, H. (1921). Arch. Derm. (Orig.), 132, 17.

-, and Georgi, F. (1921). Med. Klin., 17, 987.

Schmid, E. E., and Velaudapillai, T. (1953). Ceyl. J. Sci. Sect. D. (Med. Sci.), 8, 157.

,$- \frac{-,}{-}$ and Ponnuswamy, N. E. L. (1953). Z. Hyg., 137, 562. 